\section{PÚRPURA CUTÁNEA EN RELACIÓN CON TAMOXIFENO}

Sr. Director:

La afectación cutánea por tamoxifeno se encuentra entre las menos frecuentes. A continuación presentamos un caso de púrpura con relación al mismo.

Se trata de una paciente de 21 años diagnosticada de adenocarcinoma de mama izquierda de $1,8 \mathrm{~cm}, \mathrm{GII}$, con ganglios negativos y receptores hormonales para estrógeno y progesterona positivos en el 60\% y $90 \%$ respectivamente. Recibió tratamiento local con mastectomía y vaciamiento axilar.

Dado que se trataba de una paciente de riesgo intermedio, se sometió a un tratamiento sistémico complementario con ciclofosfamida, metotrexato y 5-fluorouracilo (esquema CMF 1 y 8 cada 21 días) por 6 ciclos con buena tolerancia y, tras ello, tamoxifeno 20 $\mathrm{mg} / \mathrm{m}^{2} /$ día.

A los 12 meses de iniciar el tratamiento hormonal refiere la aparición de varias lesiones de color rojo intenso levemente pruriginosas localizadas en la cara anterior del muslo derecho y cara anterior de ambos brazos, que no se modificaban al presionar. No tenía afectación del estado general ni otra sintomatología. La exploración mostró lesiones purpúricas, confirmadas por biopsia cutánea (extravasación eritrocitaria y discreto infiltrado inflamatorio linfohistiocitario de carácter inespecífico).

El hemograma, la coagulación, perfiles y proteinograma fueron normales. Se revisó la medicación que tomaba a fin de encontrar algún causante de lesiones purpúricas, y sólo tomaba tratamiento hormonal.

La paciente comenzó tratamiento esteroideo tópico sin notar mejoría pero sí al discontinuar la toma de tamoxifeno durante un mes, con aparición de nuevas lesiones al reintroducir el fármaco.

Se decide realizar un ciclo de esteroides orales, deflazacort $60 \mathrm{mg} /$ día, que fue poco efectivo con aclaración parcial de las lesiones conocidas sin aparecer nuevas.
Completó tratamiento hormonal durante 5 años sin otra toxicidad.

Tamoxifeno es un antiestrógeno no esteroideo que se usa como tratamiento complementario en el cáncer de mama con receptores hormonales positivos, al demostrar aumento de supervivencia y del intervalo libre de enfermedad en pacientes de estas características independientemente de su estado menstrual ${ }^{1}$. Es un fármaco bien tolerado en la mayoría de los casos, siendo sus efectos secundarios más frecuentes digestivos, sofocos, retención de líquido, fenómenos tromboembólicos e hiperplasia endometrial con sangrado ${ }^{2}$. La afectación cutánea es rara y está descrita la aparición de exantema ${ }^{3}$, en un caso erupción maculopapular de forma diferida ${ }^{4}$ y en otro púrpura en relación con vasculitis ${ }^{5}$.

En nuestra paciente, como en los pocos casos encontrados en la literatura, no existe ninguna causa que justifique la aparición de púrpura; esto, unido a la mejoría de las lesiones con la retirada y la reaparición con la introducción, apoya la causalidad del mismo.

\section{Bibliografía}

1. EBCTCG. Tamoxifen for early breast cancer: an overview of the randomised trials. The Lancet 1998;355: 1451-67.

2. Cobelli S, Dambrosio M, Farina G, et al. Long term toxicity in adjuvant treatment with tamoxifen. J Chemother 1997;9 (4):300-3.

3. Brunisma W. A guide to drug eruptions. Oosthuizen, The Netherlands: The file of Medicines, 1987;p. 93.

4. Descamps V, Bouscarat F, Boui M, et al. Delayed appearance of maculopapular eruptions induced by tamoxifen. Ann Dermatol Venerol 1999;126(10):716-7.

5. Drago F, Arditi M, Rebora A. Tamoxifen and purpuric vasculitis. Ann Intern Med 1990;112:965-6.

Amelia López-Ladrón y Manuel Ruiz Borrego Oncología Médica. Hospital Universitario Virgen del Rocío. Sevilla. 